\title{
Las instituciones del Reino de Navarra en el debate histórico jurídico de la revolución liberal
}

\section{Richard Hocquellet}

\section{Q OpenEdition \\ 1 Journals}

Édition électronique

URL : https://journals.openedition.org/ahrf/8893

DOI : $10.4000 /$ ahrf.8893

ISSN : 1952-403X

\section{Éditeur :}

Armand Colin, Société des études robespierristes

\section{Édition imprimée}

Date de publication : 1 mars 2007

Pagination : 216-218

ISSN : 0003-4436

\section{Référence électronique}

Richard Hocquellet, «Las instituciones del Reino de Navarra en el debate histórico jurídico de la revolución liberal », Annales historiques de la Révolution française [En ligne], 347 | janvier-mars 2007, mis en ligne le 21 juillet 2008, consulté le 23 avril 2022. URL : http://journals.openedition.org/ahrf/8893 ; DOI : https://doi.org/10.4000/ahrf.8893

Ce document a été généré automatiquement le 23 avril 2022.

Tous droits réservés 


\title{
Las instituciones del Reino de Navarra en el debate histórico jurídico de la revolución liberal
}

\author{
Richard Hocquellet
}

\section{RÉFÉRENCE}

Jean-Baptiste Busaall, en collaboration avec Lartaun de Egibar Urrutia, Las instituciones del Reino de Navarra en el debate histórico jurídico de la revolución liberal, Pamplona, Universidad Pública de Navarra, 2006, 234 p., ISBN 84-9769-103-2, $15 €$.

1 Jean-Baptiste Busaall est historien du droit constitutionnel et dans ce livre il se montre à la fois historien et juriste. Historien dans son attention au contexte mais surtout aux problématiques du temps qu'il étudie. Juriste dans son attention aux notions, aux concepts mais aussi à leur utilisation, à leur articulation théorique et pratique. Il propose, dans ce livre en collaboration avec un homologue espagnol, Lartuan de Egibar Urrutia, une réflexion mêlant les deux approches à partir de la première élaboration constitutionnelle moderne en Espagne.

2 Pendant la Guerre d'Indépendance, les patriotes qui luttent contre l'invasion napoléonienne et surtout contre le changement dynastique imposé par l'empereur, procèdent à une véritable révolution politique concrétisée par la proclamation de la Constitution de Cadix en mars 1812. Elle peut être considérée à juste titre comme la référence fondamentale du libéralisme espagnol (et plus largement sud-européen). L'étude présentée ici par Jean-Baptiste Busaall se centre sur un des débats les plus féconds de la période, quand les patriotes qui dirigent l'Espagne résistante cherchent à établir les bases d'un nouveau régime qui assurerait à la fois leur légitimité et la réforme d'une monarchie qui venait de prouver sa faillite. S'étant d'abord entendus sur la convocation d'une assemblée des représentants de la nation, leur tâche est de lui fixer des objectifs autres que la simple reconnaissance du pouvoir exercé de fait par 
eux-mêmes depuis les abdications de la famille royale. L'idée de l'élaboration d'une constitution a pris corps peu à peu entre le mois de juin 1808 et le mois de mai 1809. À partir de l'été 1809 , c'est-à-dire un an avant la réunion des Cortes à Cadix, le débat au sein de l'élite éclairée des patriotes porte sur la forme que devrait avoir la constitution idéale de la monarchie espagnole. Après l'ouverture des Cortes, le débat se poursuit de façon plus formelle à l'intérieur de l'assemblée et principalement au sein de la commission chargée de préparer le texte constitutionnel. La première partie du livre reprend ce débat à travers un thème qui parcourt tout le discours patriotique politique quand il traite de constitution : les lois fondamentales de la monarchie. Cette référence récurrente renvoie à un imaginaire qui peut paraître au premier abord traditionnel mais qui est aussi largement polémique dans la mesure où plus ou moins explicitement, elle stigmatise le régime juste antérieur qui ne les aurait pas respectées.

L'auteur démonte toute l'ambiguïté de l'énoncé. Sous couvert d'un retour à une pureté des origines de la monarchie, il serait possible d'établir un nouveau régime sans faire de révolution à la française. Les réformateurs les plus libéraux qui travaillent pour la Junte centrale durant l'automne 1809 réussissent même à escamoter la question de la description de ces lois en ne reprenant que certaines grandes lignes qui serviraient de base pour un régime monarchique où le pouvoir souverain reviendrait finalement à la nation à travers ses représentants. D'autres auteurs se sont néanmoins attelés à chercher dans les constitutions historiques des différentes composantes de cette ancienne monarchie plurielle les éléments utiles au débat. L'ancien royaume d'Aragon qui a perdu ses particularités institutionnelles suite à la victoire de Philippe V à la fin de la Guerre de Succession d'Espagne, est le plus souvent cité comme modèle d'une monarchie tempérée. Valence, la Catalogne, les provinces basques également, présentent des exemples de régimes où le roi ne peut que ce que veut bien concéder le peuple à travers des organes représentatifs. Jean-Baptiste Busaall note toutefois que face à la richesse de cette pluralité institutionnelle des Espagnes pré-bourboniennes, les références dans les écrits d'époque ne sont pas aussi nombreuses que l'on pourrait croire.

4 Un cas est traité à part : celui du royaume de Navarre. Tout d'abord parce qu'il est le seul à avoir conservé ses institutions après l'avènement des Bourbons et aussi parce qu'un ancien magistrat, député aux Cortes de Cadix, Benito Hermida publie à son sujet une contribution au débat intitulée Breve noticia de las Cortes, gobierno ó llamase Constitución del reyno de Navarra (1811).

5 La troisième partie de l'étude de Jean-Baptiste Busaall lui est consacrée ainsi que l'article de Lartaun de Egibar Urrutia qui clôt l'ouvrage. Pour présenter rapidement ce texte, en suivant nos auteurs, il est patent que tout le travail de Hermida consiste à vanter les mérites des Fueros navarrais comme modèle d'une monarchie à la souveraineté partagée entre le roi et ses sujets réunis en corps au sein des Cortes. Bien que magistrat, il est pris souvent en défaut par nos deux juristes d'imperfection conceptuelle ou d'imprécision notionnelle. Il parait évident que nous lisons une sélection tactique des normes politico-juridiques du royaume de Navarre pour montrer les avantages du pactisme tel qu'il a pu être idéalisé par les Espagnols éclairés qui cherchaient à lutter contre le despotisme ministériel d'un Godoy et repris lors de l'arrivée de Joseph Bonaparte par les patriotes qui refusaient de le reconnaître pour souverain. Il est tout aussi évident que Hermida cherche à peser dans le débat pour empêcher l'introduction d'un régime nouveau (libéral dira-t-on) plus inspiré des 
révolutions européennes et américaines que d'un passé exemplaire de l'Espagne. En identifiant implicitement les fueros aux lois fondamentales, en les « constitutionalisant ", Hermida en fait l'expression du pacte originel d'où découle un pouvoir certes partagé mais absolu dont découle la soumission de tous (roi comme sujets) à la loi. Ainsi, la référence à la Navarre dans le débat de la révolution libérale est teintée d'un fort traditionalisme par rapport à celle touchant à l'Aragon.

6 À rebours, il est tentant de considérer ces références historico-juridiques comme des «instrumentalisations» à des fins de politique immédiate. L'article de Lartaun de Egibar, comparant le texte de Hermida avec d'autres textes historiques sur le royaume de Navarre ainsi qu'avec les codes eux-mêmes montre bien qu'il n'y a pas de vérité intangible même dans ce domaine qui semble si figé de par sa fonction et son langage.

7 À lire de plus près ce que peuvent nous inspirer des études aussi rigoureuses que celles présentées ici, c'est toute la dimension plastique des textes normatifs permettant une certaine créativité de la part des acteurs qui se dévoile et nous amène à penser plus loin. Au-delà d'une apparente transcendance, le discours juridique peut être approprié et les acteurs peuvent en adapter le contenu aux pratiques de leurs temps, à leurs objectifs, à leur horizon créant du coup un nouvel énoncé, relançant ainsi son usage. 